\title{
Research on Dance Motion Simulation Based on Virtual Reality Technology
}

\author{
Zhang Yi \\ School of Physical Education, Jianghan University, Wuhan Hubei，430056, China \\ zhangyijh@126.com
}

Keywords: virtual reality, dance teaching, motor skills

\begin{abstract}
This paper introduces the domestic and international exploration in virtual reality teaching system in dance and related fields to promote dance education reform and advance the dance education informatization. The development of the domestic dance teaching virtual reality system is in the initial stage, while it is burgeoning in American and Japan, which provide reference and examples. On this basis, this paper discusses the user requirement, function demands and composition of dance teaching virtual reality system, and prospects for the future dance teaching virtual reality system.
\end{abstract}

\section{Introduction}

Dance is a practical discipline. In its teaching process, most knowledge and skills and information need students to imitate and feel the teacher's dancing actions. The practical and strong dance teaching is very difficult, like the teaching of other subjects, to adopt modern educational methods such as network teaching and distance teaching. Because in these teaching methods, students only by watching the action teaching video for learning, it is difficult to obtain the performance of dance movements, emotions and feel personally on the scene, the teachers and students to study the effect of action can not be timely evaluation and feedback. At the same time, the traditional classroom teaching method is limited by time and space after all, and the students' review of learning content will be affected after class. The application of virtual reality technology provides the possibility to solve these problems to a great extent. Virtual reality technology, as a new human-machine interaction method in the computer field, can provide users with a three-dimensional virtual world similar to the real world. It has the characteristics of immersion, interaction and imagination. Virtual reality system can through the helmet, gloves and other equipment to receive input from a user action or other instruction information processing in the system and influence by some output devices on people's visual, auditory and tactile sense, makes people like some behavior in the real world the same feeling. In recent years, virtual reality technology has gradually entered the vision of the educators, and has achieved rapid development in the field of education and teaching reform. Especially in some practical subject education, the application of virtual reality technology has been paid more attention by the educators. In the traditional way of education, students can only acquire knowledge through practice, and the learning process can be completed in virtual environment, which greatly reduces the cost of practice teaching, and also solves the problem of time and space limitation in traditional practice teaching. Dance teachers have also begun to realize the advantages of virtual reality technology in dance teaching.

\section{Analysis of Current Situation of the Application of Virtual Reality Technology in Dance Teaching}

Virtual reality system can feedback participants' actions and create participants' immersive feelings in the virtual world, so it has been applied in the field of motion training for a long time. Movement training and dance teaching has great similarity, the development of virtual reality system in the field of training action started earlier, the foundation for the development of virtual 
reality system of dance teaching, the author first on action training in the field of virtual reality practice simple comb. After the application of virtual reality design into motion capture technology, human-computer interaction level has been greatly improved, because in the virtual reality system can introduce some elements of the game, players can get more fun action in human-computer interaction, achieve better effect of training. Some virtual reality application systems are devoted to the replacement of the traditional teaching methods of teachers and apprenticeship by the new way of action training. Using action capture technology, the computer system can track the learner's action track and supervise and correct it. The experiment of the project group shows that some recruits have made obvious progress in the training of attack and defense after the training of virtual reality system. This shows that the feedback information of the virtual system can play a role in action learning.

The practice of virtual reality in the field of training more action in teaching methods, human-computer interaction, technology and other aspects of the first attempt, for the development and design of virtual reality system applied in dance teaching has laid a certain foundation in theory and technology. Currently, researchers have carried out the research and development of virtual reality system for dance teaching. The timing vibration device is mainly used to remind the time point of the learner's action, while the self shifting screen shows the specific process of the action to the learner. The system will generate a real-time virtual image on the screen based on the actions of learners, so that learners can observe the difference between their actions and teaching actions. The eight villages have developed a set of dance training on the basis of the integration of action capture and virtual reality technology. Learners need to wear a helmet mounted display. The picture in the monitor is made up of the virtual images of the two dances, one is the action image of the professional dancer, and the other is the virtual image composed by the learner's own dance movements. Through the contrast of two virtual images, the learners can easily find the difference between their actions and the movements of the professional dancers. In this system, the imitating action of learners is synchronized with the action of virtual images, which, to a certain extent, also requires higher learners' experience. The user needs to wear a special suit to capture the action information, and then imitate the dance movements of the virtual teacher to learn the dance. After the imitation system will be completed, to learn the user's feedback, including the completion of the fractional degree of feedback, will be compared to dance dance users virtual image and virtual teachers and find out the action on the wrong part of each part of the action. Because this teaching system is more detailed in setting up the action capture point, so the system can collect enough data to feedback and evaluate the learning situation of users. At present, the practice of virtual reality system in dance teaching in China is just beginning, and the development of the system is not only for dance teaching, but also has many functions such as choreography, dance production and so on. In addition, the development practice of virtual reality system for a particular style of dance has also become the characteristic of the research in this field.

Users can arrange choreography in 3D animation. On the basis of virtual dance simulation visual system, the computer aided teaching of Dance Majors can also be carried out. The user can use the system to learn the choreography or dance movement of the dance according to its own needs. Users can also set the number of virtual dancing figures according to their needs, including music and scenes, even dancing images. The 3D dance visualization system mainly focuses on the application design of choreography, although it has the function of computer aided dance teaching, but the function is relatively simple. Guo Jin and others used the technology of dance virtual reality in the study of robot dance. The team first analyzed the rules and methods of robot dance movements in computer system, and established the database of key frames of dance movements. The transition function of the key frame of the dance movement is used to test the transition and smooth of the robot's dance movement. The experiment uses the NOBODY robot dance video to realize the dance animation of a three-dimensional virtual human skeleton model of the imitation robot. Study on Virtual Simulation of Chen Qixiang et al of dance oriented chime to chime movement style on the basis of the research and development of dedicated chime dance virtual system, in order to make the development of library system arrangement and provide basis for the 
chime music dance.

\section{Design Requirements of Virtual Reality System in Dance Teaching}

The design of virtual reality system applied to dance teaching should meet the following requirements:

First, the virtual reality system of dance teaching should enable the participants of the teaching to produce real experience. Because dance teaching has a strong practicality, teaching process needs to be vivid, and teachers' subtle movements and expressions will have an impact on teaching effect and students' psychology. Therefore, for the virtual reality system of dance teaching must be able to make teaching participants as in dance classroom experience, that is to make students in the virtual world of data generated as learning to dance in the middle of the classroom illusion, so as to make the students devote themselves to learning the dance. If the virtual reality system does not reach such a requirement, it will distract the user's attention, and it is difficult to immerse people in the learning atmosphere of the dance. In order to achieve this goal, the virtual reality system applied in dance teaching should be on the user's senses of sight, hearing, touch and other forms of stimulation, and fully mobilize the human sensory organs, make the teaching process to stimulate the effect is closer to the traditional teaching mode, the user's real experience personally on the scene. Secondly, the virtual reality system, which is applied to dance teaching, can provide users with real-time and convenient means of human-computer interaction, and the operation is simple and practical. A simple and practical operating system is also a prerequisite for users to produce real experience. Users can easily input their dance motion information into the system, and get real-time feedback information from virtual reality system, allowing users to make timely adjustments. In order to meet the requirements for virtual reality system, the dance teaching must have real-time and convenient means of human-computer interaction, no delay, computer equipment but also to have the ability of high-speed computing to deal with a large amount of data, or when people interact with the computer will appear obvious time delay, will make users different from the traditional teaching mode of psychological experience and realistic influence in the process of teaching, reduce the teaching effect.

To learn a dance, students first need to see the professional dance demonstration. Therefore, presentation is also the most basic functional requirement of the virtual reality system of dance teaching. In addition to the need for animations in the initial observation stage, the animation presentation of virtual teachers also needs to appear on the screen for students to learn during the stage of student imitation. Just observe the dynamic 3D image of dance also not highlight the virtual reality system in the field of dance teaching, dance teaching should also be able to real-time virtual reality system of students of the dance movements captured and presented on the screen, the students also need to imitate dance and dance compared virtual teacher to find out the differences, so we can better feedback on students' learning behavior, improve students' learning effect. Scientific guidance is of great importance for improving students' learning efficiency and learning efficiency. The virtual reality system of dance teaching can achieve the guidance of students' learning behavior through various ways of feedback. Dance teaching of virtual reality system feedback can include: comparative observation system presents the students' dance, dance and dance students observe virtual teacher (such as the action part differences marked in red), scores of time periods of parts, etc. In order to meet the above requirements and functional requirements, the virtual reality system of dance teaching should consist of four elements: three dimensional mapping system, action matching system, dance action database and motion capture system. The motion capture system is used to obtain the action of the user information, and by the action, system will be compared with the movements of data in the database, and the 3D graphics system is responsible for the image obtained according to the dance dance teacher virtual database generated dance image and motion capture system users appear on the screen to make visualization. 


\section{Application Prospect of Virtual Reality Technology in Dance Teaching}

The wide application of virtual reality technology in the field of education is an inevitable trend of future education development. The rapid development of virtual reality technology will lead the development direction of educational reform. For the more practical dance discipline, it is more affected. The vividness and immediacy of the dance teaching will have a key influence on the students' learning effect. Although traditional teaching has all these advantages, it can not adapt well to the requirements of education and teaching in the information age. Video teaching alone has stripped the vitality of dance teaching itself, and its effect is not satisfactory. The application of virtual reality technology in the field of dance teaching can solve these problems to a large extent, the information age teaching method and traditional dance teaching to combine the advantages of both maintained a vivid and contemporary teaching, and make the dance teaching itself breakthrough the limitation of time and space, so that it can better adapt to the development of the future direction of education. Virtual reality technology will have broad development space in the field of dance education and teaching in the future. Especially in the digital teaching reform of dance, virtual reality technology will play an unprecedented important role.

On the one hand, the development and utilization of virtual reality system used in dance teaching makes it possible for the distance education of dance. Compared with other subjects teaching, dance teaching practice is more prominent, more dependent on the traditional classroom communication between teacher and student's oral teaching. Therefore, in many subjects, distance education has formed a mature mode today, and the distance teaching of dance education is slow to start. A mature virtual reality system of dance teaching can act on the senses of teachers and students in an all-round way, so that they can get almost the same teaching experience as traditional classroom. The remote education which can be used in distance education is convenient and flexible, but also for the learners to bring full sensory experience, greatly improve the distance education dance teaching effect, so that this new digital teaching means into the dance education fields possible. On the other hand, the development and utilization of virtual reality system for dance teaching can also greatly improve the current teaching level of dance class, improve students' learning efficiency and improve teaching effectiveness. Due to the limitation of teaching resources and teaching time and space, there is a limited number of repetitions in the same classroom teaching content, so it is difficult for students to have repeated exercises under the guidance of teachers. Dance teaching virtual reality system that classroom teaching resources become a kind of digital resources, students can repeatedly watch in class exercises, and can provide the system according to the feedback data constantly adjust their own learning process, the realization of this process will greatly promote the students' learning effect from.

From the perspective of this research, the research and development of virtual reality system in dance teaching in the world is in the ascendant, but not enough attention has been paid in the field of educational technology in China. From the theoretical point of view, the development of virtual reality system for dance teaching still needs more theoretical research as support. From a technical perspective, the development of virtual reality system of dance teaching needs more talents and financial support.

\section{References}

[1] R. Sidharta, and C. Cruz-Neira. Cyclone Uppercut, a Boxing Game for an Immersive Environment[J]. Advances in Computer Entertainment Technology, 2005, (6):363-364.

[2] Z. Yang, B. Yu, R. Diankov, W. Wu, and R. Bajscy. Collaborative Dancing in Tele-Immersive Environment[A]. ACM. 06 Proceedings of the 14th annual ACM international conference on Multimedia[C]. New York: ACM,2006.723-726.

[3] P.T. Chua, R. Crivella, B. Daly, N. Hu, R. Schaaf, D. Ventura, T. Camill, J. Hodgins, and R. Pausch. Tai Chi: Training for Physical Tasks in Virtual Environments[J]. Virtual Reality, 2003, 
(3):87-94.

[4] T. Komura, B. Lam, R.W.H. Lau, and H. Leung. E-Learning Martial Arts[J]. Web-Based Learning, 2006, (6):239-248.

[5] D. Davcev, V. Trajkovic, S. Kalajdziski, and S. Celakoski. Augmented Reality Environment for Dance Learning[J]. Information Technology: Research and Education, 2003, (8):189-193.

[6] A. Soga, B. Umino, and M. Hirayama. Automatic Composition for Contemporary Dance Using 3D Motion Clips: Experiment on Dance Training and System Evaluation[J]. Cyber-Worlds, 2009, (9):171-176.

[7] A. Nakamura, S. Tabata, T. Ueda, S. Kiyofuji, and Y. Kuno. Dance Training System with Active Vibro-Devices and a Mobile Image Display[A]. IEEE/RSJ International Conference. Intelligent Robots and Systems[C]. New York: IEEE,2005.3075-3080.

[8] K. Hachimura, H. Kato, and H. Tamura. A Prototype Dance Training Support System with Motion Capture and Mixed Reality Technologies[A]. IEEE Int'l Workshop. Robot and Human Interactive Comm [C]. New York: IEEE, 2004. 217-222.

[9] Jacky C.P. Chan, Howard Leung, Jeff K.T. Tang, and Taku Komura. A Virtual Reality Dance Training System Using Motion Capture Technology[A]. IEEE Transactions on Learning Technologies[C]. New York: IEEE, 2011. 187-195.

[10] F.C. Virtual dance simulation visual system design [J]. equipment manufacturing, 2009, (12): 109. 